\title{
Similarities and differences in the functions of nonsuicidal self-injury (NSSI) and sex as self- injury (SASI)
}

Linda J onsson, Carl Göran Svedin, Gisela Pribe, Cecilia Fredlund, Marie Wadsby and Maria Zetterqvist

The self-archived postprint version of this journal article is available at Linköping University Institutional Repository (DiVA):

http:// urn.kb.se/ resolve?urn=urn:nbn:se:liu:diva-144486

N.B.: When citing this work, cite the original publication.

J onsson, L., Svedin, C. G., Pribe, G., Fredlund, C., Wadsby, M., Zetterqvist, M., (2017), Similarities and differences in the functions of nonsuicidal self-injury (NSSI) and sex as self-injury (SASI), J ournal of Suicide and Life-threatening Behaviour. https:// doi.org/ 10.1111/ sltb.12417

Original publication available at:

https:// doi.org/ 10.1111/sltb.12417

Copyright: Wiley (24 months)

http:// eu.wiley.com/WileyCDA/ 


\begin{abstract}
Differences and similarities were studied in the functions of two different self-injurious behaviors (SIB): nonsuicidal self-injury (NSSI) and sex as self-injury (SASI). Based on type of SIB reported, adolescents were classified in one of three groups: NSSI only ( $n=910)$, SASI only $(n=41)$ and both NSSI and SASI $(n=76)$. There was support for functional equivalence in the two forms of SIB, with automatic functions being most commonly endorsed in all three groups. There were also functional differences, with adolescents in the SASI only group reporting more social influence functions than those with NSSI only. Adolescents reporting both NSSI and SASI endorsed the highest number of functions for both behaviors. Clinical implications are discussed, emphasizing the need for emotion regulation skills.
\end{abstract}




\section{INTRODUCTION}

Self-injurious behaviors (SIB) are common in adolescents. Such behaviors can be direct, such as nonsuicidal self-injury (NSSI), or indirect, such as mistreating and abusing oneself (Nock, 2010). NSSI is defined as the deliberate destruction of body tissue without suicidal intent, referring to behaviors such as cutting, burning and scraping skin (International Society for the Study of Self-Injury [ISSS], 2007). It is of special interest due to its inclusion as a condition in need of further study in the fifth version of the Diagnostic and Statistical Manual of Mental Disorders (American Psychiatric Association, 2013). International studies have shown prevalence rates of 15-20\% in adolescents (Muehlenkamp, Claes, Havartape \& Plener, 2012), and in a Swedish study of community adolescents approximately one third reported having tried NSSI at least once during the last year (Zetterqvist, Lundh, Dahlström \& Svedin, 2013).

SIB can also be indirect, such as reckless and destructive behaviors where individuals mistreat and abuse themselves, for example by alcohol abuse, involvement in abusive relationships, binge eating and starvation (Favaro, Ferraram \& Santinastaso, 2007; Møhl, La Cour \& Skandsen, 2014). There is currently an ongoing discussion as to how different SIB should be defined, conceptualized and categorized in relation to each other (Hooley \& St. Germain, 2014). According to St. Germain \& Hooley (2012), indirect selfinjurious behavior can be understood as a behavior that is clearly damaging to the self but does not involve immediate and deliberate damage to body tissue. They have further suggested that indirect self-injurious behavior should be clinically significant, repetitive or persistent and represent a source of serious concern for clinicians or family members as well as having the potential to lead to marked physical damage over time. 
Direct and indirect SIB often co-occur, such as eating disorders and NSSI, for example (Claes \& Muehlenkamp, 2014), as well as risky sexual behaviors and cutting in adolescents (DiClemente, Ponton \& Hartley, 1991; Svensson, Fredlund, Svedin, Priebe \& Wadsby, 2013). Despite their topographic difference, these behaviors often share common elements, such as using the body to regulate the state of mind as well as the social situation (Brausch \& Muehlenkamp, 2014). Recent studies, however, have also shown support for a distinction between direct and indirect types of SIB. Individuals with NSSI, for example, have shown to report more suicide attempts and to be more self-critical than those who engage in indirect forms of SIB (St. Germain \& Hooley, 2012), suggesting that the behaviors are best described as separate phenomena (Hooley \& St. Germain, 2014; Møhl et al., 2014; Nock, 2010; St Germain \& Hooley, 2012). Despite being harmful and abusive to the individual and often associated with negative consequences in the long run, the answer to why adolescents engage in maladaptive behaviors (Wedig \& Nock, 2010) is usually found in the underlying purpose of the self-injurious behavior, i.e., to cope with and relieve distress and problems (Claes \& Vandereycken, 2007). Since the behaviors chosen to reach this goal can vary in one and the same individual, a functional approach can therefore be useful in understanding and treating such behaviors (Wedig, 2014).

A recent area of interest in the field of indirect self-injury is reflected in clinical reports of adolescents and young adults who testify to deliberately using destructive sexual activities as a means of self-injury (Jenstav \& Meissner, 2016; Jonsson \& Lundström Mattsson, 2012). In a report from the Swedish Children’s Welfare Foundation (Jonsson \& Lundström Mattsson, 2012), partly based on qualitative interviews, a suggestion was put forward that sex as self-injury could be defined as: "when a person has a pattern of seeking sexual situations involving mental or physical harm to themselves. The behavior causes significant distress or impairment in school, work, or other important areas”. In the report, 
which was also based on clinical experience and interviews with adolescents and professionals, a model was presented for understanding repeated sexual risk-taking in the form of sex as self-injury. In this model the key force underlying SASI was the presence of unbearable feelings, especially intense anxiety. In the report the interviewed individuals described different behaviors when using sex as self-injury, such as attending sexual meetings where they knew that they would get physically hurt or would lack control of the sequence of events. In one recent qualitative interview study (Jonsson, Svedin \& Hydén, 2015), some of the young women interviewed compared their engagement in selling sex to cutting, and often had experience of both. Perhaps risky sexual behaviors and intentional engagement in physically abusive sexual relationships can be classified as indirect self-injury in accordance with the definition of St. Germain \& Hooley (2012) and Hooley \& St. Germain (2014). At the same time, in some instances of intentional self-abusive sexual behaviors direct physical harm might be involved as well as direct damage to body tissue, which is more in line with the definition of direct self-injurious behavior. More empirical data are thus needed in the process of establishing how this behavior should be conceptualized, defined and categorized.

The functions of NSSI have by now been extensively investigated (e.g., Klonsky, 2007). There is general consensus that the behavior has an affect regulation function, increasing or decreasing affect. For nonclinical adolescents in particular, social functions are not unusual, but are typically considered secondary to affect regulation (Dahlström, Zetterqvist, Lundh \& Svedin, 2015). There is support that difficulties regulating emotions are associated with several maladaptive behaviors (Tull, Weiss, Adams \& Gratz, 2012). A functional perspective can thus be useful in clinical practice to understand and treat these goal-directed behaviors, where negative emotions usually precede several maladaptive behaviors (Wedig, 2014). In this approach, previous research has found that both NSSI and 
suicide attempts were performed in order to relieve negative emotions, for example (Brown, Comtois \& Linehan, 2002), but differences in functions have also been reported (Brown et al., 2002; Chapman \& Dixon-Gordon, 2007). Furthermore, a previous model of functions for NSSI was found to be applicable to female binge eating and purging, using the same functional assessment instrument (Wedig \& Nock, 2010). There is thus an overlap in functions between the topographically different behaviors of eating disorders and NSSI (Wedig, 2014), with both behaviors serving to regulate strong negative emotions and generate feelings, as well as social functions (to receive attention or help and/or to decrease demands from others).

In a study by Cooper, Sharpio and Powers (1998) motivations for sex and risky sexual behavior among adolescents and young adults were studied from a functional perspective. They found that different factors promote and maintain risk-taking and that there was no common set of predictors. Experience of negative emotions may promote indiscriminate sexual contacts among individuals who rely on sex as a way of coping with these emotions, for example. On the other hand, situational cases such as the presence of an attractive and available sex partner may better account for indiscriminate sexual behaviors among those who are primarily motivated by enhancement needs. This notion of indiscriminate sexual contacts was supported in a recent qualitative interview study of 15 young women selling sex, both in an online and offline environment (Jonsson et al., 2015). The women described how they used sex in this context to regulate both negative and positive feelings, and regarded it as a form of strategy that enabled them to cope with life. In this respect they compared selling sex to other SIB, such as cutting.

However, there are very few studies with a functional approach that compare the functions of different SIB in the same study sample. To our knowledge, little work has been done comparing how functions can vary in different SIB in adolescents. This study 
contributes the first empirical data in the process toward establishing how sex as self-injury should be conceptualized, defined and categorized by exploring the functions of NSSI vs. sex as self-injury (SASI).

The present study was exploratory and aimed at examining which functions are reported for NSSI and which functions are endorsed by adolescents who report that they have used sex as self-injury (SASI), and furthermore to compare whether the functions of these different behaviors are similar or different. Do adolescents with NSSI endorse different functions for engaging in the behavior compared to adolescents with SASI? Do adolescents who have engaged in both NSSI and SASI report different functions for respective behaviors? Do reported functions differ for adolescents reporting only one type of SIB compared to adolescents who engage in both NSSI and SASI?

\section{METHOD}

\section{Procedure}

A representative sample of Swedish high school seniors (in their third year at the Swedish high school) was selected by Statistics Sweden using information from the Swedish school register. In Sweden about 91\% of all 18-year-old adolescents were enrolled in Swedish high schools, according to data from 2013 (Statistics Sweden, 2014). Schools were selected by Statistics Sweden using stratification on the basis of school size and study program, according to the National School Register for the second year of Swedish high schools for the autumn of 2013. One or two study programs were selected from each school. An oversampling was carried out for Stockholm, the capital of Sweden, to make it possible to compare the county of Stockholm with the rest of the country. 
Distribution and collection of questionnaires were performed by Statistics Sweden. Information about the study was sent to the principal of the selected schools by mail in August 2014. Participating schools answered the questionnaire in digital format (by computer in 165 schools) or, when computers were not available, on paper (six schools). A reminder for the schools that had not yet delivered data was given by phone within a month. Information about the study was given to the principal, the teachers in charge when the questionnaires were filled in and the students. The students gave informed consent for participation by answering the questionnaire. Afterwards they received written information about where to turn for help and support if needed after answering the questionnaire.

The study was approved by the Regional Ethical Review Board of Linköping (Dnr, 131-31).

\section{Participants}

A total of 13,903 adolescents from 261 out of 1,215 Swedish high schools were selected by Statistics Sweden from the Swedish National School Register in the autumn of 2013. Of the 261 schools selected, 238 were still in existence and still provided the selected programs in 2014. For additional statistical power, the extra sample from the county of Stockholm was included in the study. The response rate for the county of Stockholm was lower $(48.7 \%)$ compared to the rest of the country (65.3\%). Differences were also seen regarding size of schools. In Stockholm fewer of the respondents came from schools with 10190 pupils (13.9\%) compared to the rest of the country $(22.1 \%)$ and more often came from middle-size schools with 191-360 pupils (51.2\%) compared to the rest of the country (41.6\%), resulting in a small effect size (Cramer's $V=.10)$. Differences between Stockholm and the rest of the country were otherwise small or non-existent when the answers to the 
questionnaire were analyzed. Almost no differences were seen between the selection sample and the sample answering the questionnaire regarding the selection criteria or size of school and study program.

In total, 171 schools with 9,773 adolescents agreed to participate in the study. Of the 9,773 adolescents that had the opportunity to participate, 5,873 completed the questionnaire. Thirty-four questionnaires were excluded due to unserious answers or a high amount of missing data, leaving 5,839 adolescents. This gave a response rate of 59.7\%. Mean age of the participating adolescents was $17.97(S D=0.63)$. In the current study 4,685 adolescents were excluded since they did not report any experience of NSSI and/or SASI (Figure 1). A further 76 adolescents did not answer the questions about NSSI or SASI and were excluded, as were an additional 20 adolescents who only answered the NSSI question but not the SASI question. Finally, 31 adolescents were excluded because they had not answered the questions concerning the functions of self-injurious behavior in the FASM questionnaire, which resulted in a total of 1,027 participants for the study.

\section{Participants' background}

Table 1 shows that $18 \%(n=1,027)$ of all participating adolescents had experience of some form of self-injurious behavior (NSSI and/or SASI). Using chi-square analysis throughout, table 1 showed significantly more girls in the self-injuring group (76.6\% vs. 50.1\%) compared to the group without any self-injurious behavior $(n=4,685)$, and individuals who felt that the division into boy or girl did not fit them (1.6\% vs. $0.8 \%)$. Regarding study programs and immigrant status no differences were shown between the groups. No differences were found regarding whether mothers were working or their education status whereas significant differences were found regarding fathers. Participants 
with experience of self-injury less often had fathers who were working (84.4\% vs. $88.6 \%)$ or who had a university education (36.4\% vs. $41.1 \%)$. The financial situation in the family was more often perceived as problematic among the participants with self-injurious behavior (25.9\% vs. $20.4 \%$ ). Finally, the adolescents with self-injurious behavior were less likely to live with both parents together or alternately (63.5\% vs.73.1\%).

\section{Measures}

The questionnaire for the present study was a modified version of the questionnaire used previously by Svedin and Priebe (2004, 2009). It comprised 116 main questions, of which only questions relating to background, self-injury behavior status and functions were used in the present study.

Non-suicidal self-injury. Screening for the NSSI was done using a general question from The Self-Injurious Thoughts and Behaviors Interview-Short Form-Self Report (SITBI-SF-SR). The SITBI-SF-SR was developed from the SITBI (Nock, Holmberg, Photos, \& Michel, 2007), a structured interview that assesses a wide range of self-injurious thoughts and behaviors. Participants who answered in the affirmative to the question: "Have you ever actually engaged in non-suicidal self-injury (NSSI; that is, purposely hurt yourself without wanting to die, for example by cutting or burning)?” went on to answer questions from The Functional Assessment of Self-Mutilation (FASM; Lloyd, Kelley \& Hope, 1997), which assesses the methods, frequency and function of self-reported deliberate NSSI. Respondents are asked whether they have engaged in any of eleven different methods of NSSI during the past year or at any time previously. The frequency of NSSI and whether medical treatment was received is also assessed, as is the degree of physical pain experienced during NSSI. The FASM contains 22 statements assessing the functions of NSSI, which respondents rate on a four-point Likert scale, covering the categories "never", "rarely", "some” and "often”. The 
FASM has previously been used in normative (Lloyd et al., 1997) and psychiatric samples (Guertin, Lloyd-Richardson, Spirito, Donaldson \& Boergers, 2001), with test scores showing acceptable psychometric properties in adolescent samples (Guertin et al., 2001; Esposito, Spirito, Boergers \& Donaldson, 2003; Penn, Esposito, Schaeffer, Fritz \& Spirito, 2003). Lloyd et al. (1997) identified two factors from the NSSI items, moderate/severe and minor. The former consisted of NSSI items that are considered to be more severe, such as cutting/carving and burning the skin. The latter consisted of items considered to be less severe, such as biting or hitting. These subscales have been used in previous NSSI studies, as for example by Guertin et al. (2001) and Zetterqvist et al. (2013).

Test scores from the FASM also support concurrent validity, demonstrating significant associations with measures of recent suicide attempts, hopelessness and depressive symptoms (Nock \& Prinstein, 2005). The psychometric properties of the Swedish version, administered to a community sample of adolescents, have been fully described in a study by Zetterqvist et al. (2013). Reliability scores of the Swedish version of the FASM for the present sample were tested with acceptable/good internal consistency. Cronbach's alpha for all the FASM functions for NSSI in the present sample was $\alpha=.86$. A previous factor analytic study (Dahlström et al., 2015) where the FASM was used on a Swedish adolescent community sample resulted in a four-factor model: automatic factor $(\alpha=.81)$, social influence factor $(\alpha=.86)$, avoiding demands $(\alpha=70)$, and peer identification $(\alpha=.66)$. These factors are used in the present study and the alpha values for the present sample are presented in parenthesis. Automatic functions include feeling generation/anti-dissociation items, selfpunishment, to get control, to stop bad feelings and to feel relaxed. Social influence functions include items aiming at influencing the social environment, for example by receiving attention, help or understanding. Peer identification refers to functional items such as feeling part of a group or being like someone you respect. Items in the avoiding demands factor 
refers to functions which decrease social demands. In the present analysis a functional item was considered to have been endorsed if it was rated as "some" or "often" and dichotomized accordingly.

Sex as a form of self-injury. Questions were created for the purpose of the study regarding using sex as self-injury: "Have you ever used sex to purposely hurt yourself?" with "Yes" or "No" as response alternatives, followed by questions about frequency of SASI during the last year. The FASM (Lloyd et al., 1997) was used to assess functions of the SASI (see NSSI and the FASM section). Cronbach's alpha for all the FASM functions for SASI in the present sample was $\alpha=.85$. Based on the four-factor model suggested by Dahlström et al. (2015), Cronbach’s alpha for the four factors were: automatic factor: $\alpha=.80$, social influence factor: $\alpha=.81$, avoiding demands: $\alpha=.60$, and peer identification: $\alpha=.53$.

Demographic information. A demographic questionnaire was drawn up for the purpose of the study, assessing demographic characteristics such as gender, type of education, parents' occupation, parents' education, perception of family's economy, immigrant background and living conditions. Adolescents self-reported demographic information in fixed answer categories (Table 1).

Data analyses. SPSS 20,0 was used for all analysis. The results are presented with frequencies and mean values. In order to analyze differences between groups, nonparametric tests (Chi ${ }^{2}$ - test, Fisher's exact text.) as well as parametric tests (t-test using insilico, http://in-silico.net/tools/statistics/chi2test/2x2) were used. 


\section{RESULTS}

For the present analyses, adolescents who confirmed any self-injurious behavior $(n=1,027)$ were classified into three groups based on their answers to the SIB-questions: NSSI only, SASI only and adolescents with both NSSI and SASI. The NSSI only group consisted of 910 adolescents, of which 207 (22.8\%) were boys, 692 (76.0\%) were girls and $11(1.2 \%)$ reported that neither category was applicable $(n=910)$. Of those who reported only SASI $(n=41), 11(26.8 \%)$ were boys, 29 (70.7\%) were girls and one person $(2.5 \%)$ reported that neither category was applicable. Seventy-six adolescents reported experiences of both NSSI and SASI, of which six (7.9\%) were boys, 66 (86.8\%) were girls and four (5.3\%) reported being neither boy nor girl. Adolescents with both NSSI and SASI $(n=76)$ are presented twice, since they answered the questions concerning the functions of NSSI and the functions of SASI separately (Figure 1).

\section{Functions of nonsuicidal self-injury (NSSI)}

Table 2 summarizes the reported functions of the different SIB in the three groups. For adolescents who reported only NSSI $(n=910)$, the function "to relieve feeling numb or empty" was most commonly reported (46.9\%), followed by "to stop bad feelings" (38.1\%) and "to punish yourself" (36.4\%). The functions in the automatic factor were reported by $18.6 \%-46.9 \%$ of adolescents with NSSI (Table 2). Social influence functions for NSSI were relatively less commonly endorsed, from $1.8 \%$ (to make others angry) to $10.4 \%$ (to try to get a reaction from someone, even if it's a negative reaction). Of those with only NSSI, $0.2 \%-1.6 \%$ endorsed functions in the peer identification factor and $2.0 \%-5.4 \%$ endorsed functions in the avoiding demands factor. For adolescents who reported having engaged in both NSSI and SASI, automatic functions for NSSI were endorsed by $43.4 \%$ 75.0\%. Social influence functions for NSSI were endorsed by $2.6 \%-22.4 \%$, while $1.3 \%-5.3 \%$ 
and $3.9 \%-11.8 \%$ of adolescents endorsed functions for peer identification and avoiding demands, respectively (Table 2).

\section{Functions of sex as self-injury (SASI)}

For adolescents who only reported engaging in SASI $(n=41)$, the function "to relieve feeling numb or empty” was most commonly reported (58.5\%), followed by "to stop bad feelings" (53.7\%) and "to punish yourself” (41.5\%). Automatic functions for this behavior were endorsed by $19.5 \%-58.5 \%$ of the adolescents. Compared to the automatic functions, social functions for sex as self-injury were less commonly endorsed, from $0.0 \%$ (to make others angry) to $34.1 \%$ (to try to get a reaction from someone, even if it's a negative reaction) of adolescents reporting social influence functions. The peer identification functions were endorsed by $2.4 \%-9.8 \%$ and functions relating to avoiding demands were reported by 7.3\%-9.8\% of adolescents with only SASI. Of those adolescents with both NSSI and SASI, 22.4\%-59.2\% endorsed automatic functions for their sexual behavior, 3.9\%-17.1\% endorsed social influence functions for SASI, whilst 0.0\%-3.9\% endorsed peer identification functions and 2.6\%-6.6\% endorsed functions in the avoiding demands factor (Table 2).

Functions of NSSI vs functions of SASI in adolescents with only NSSI or only SASI

Adolescents with only NSSI or only SASI were compared to examine if they differed concerning which automatic and social influence functions were reported for respective behaviors. The groups followed the same pattern of functional endorsement with the automatic functions being most commonly endorsed and social functions relatively less so (Table 2). Significantly more adolescents in the SASI only group endorsed functions in the

social influence factor: “to get attention”, $26.8 \%$ vs 9.3\%, $\left(\chi^{2}(1, N=910 / 41)=13.22, p=\right.$ 
$.0003)$ and "to try to get a reaction from someone, even if it's a negative reaction", $34.1 \%$ vs $10.4 \%\left(\chi^{2}(1, N=910 / 41)=21.73, p<.0001\right)$. The function "to feel more a part of a group" was also reported by significantly more adolescents in the SASI only group compared to those with only NSSI, 9.8\% vs $0.9 \%,\left(\chi^{2}(1, N=910 / 41)=24.81, p<.0001\right)$, as was "to give yourself something to do when alone”, $26.8 \%$ vs 5.4\%, $\left(\chi^{2}(1, N=910 / 41)=30.52, p<.0001\right)$. Of all 22 functions, those with only SASI endorsed an average of $4.12(S D=3.00)$ functions compared to $2.63(S D=2.87$ ) reported by those with only NSSI, which was significantly higher $(\mathrm{t}=3.25, p=.001)$. The average number of reported automatic functions was 2.41 (SD $=1.76)$ in the SASI group compared to $1.92(S D=1.89)$ in those with NSSI, which was not significant $(\mathrm{t}=1.63, p=.10)$. The average number of reported functions in the social influence factor was $0.95(S D=1.16)$ vs $0.48(S D=1.24)$ with the SASI group reporting significantly more social influence functions $(\mathrm{t}=2.38, p=.02)$.

Functions of NSSI vs functions of SASI in adolescents with both NSSI and SASI

The 76 adolescents that had experience of both NSSI and SASI began by answering the questions concerning NSSI functions, and then went on to the SASI question and functions. The level of NSSI severity in the only NSSI group compared to the NSSI+SASI group was assessed by adding together the percentages of adolescents who endorsed each item on the moderate/severe NSSI behavior subscale. Compared to adolescents with only NSSI, the 76 adolescents in the NSSI+SASI group reported more severe NSSI: 35.5\% reported 3-5 moderate/severe NSSI behaviors compared to $15.0 \%$ in the NSSI only group. Specifically, 76.3\% of those with NSSI+SASI endorsed cutting/carving skin compared to $50.7 \%$ in the NSSI only group $(\mathrm{p}<0.001$, phi $=.14)$. Furthermore, the NSSI+SASI group endorsed several of the 11 NSSI methods of the FASM: $5.04(S D=3.1)$ compared to 3.06 $(S D=2.6)$ for the NSSI only group $(\mathrm{p}<0.001)$. 
There were no differences in the proportion of adolescents who endorsed the social influence functions for respective behaviors (Table 2). However, significantly more adolescents of those with both NSSI and SASI endorsed the following automatic functions for NSSI compared to SASI: "to get control of a situation" $53.9 \%$ vs $31.6 \%\left(\chi^{2}(1, N=76)=\right.$ 7.77, $p=.005)$, “to stop bad feelings" $69.7 \%$ vs $43.4 \%\left(\chi^{2}(1, N=76)=10.72, p=.001\right)$ and "to feel relaxed" $43.4 \%$ vs $22.4 \%\left(\chi^{2}(1, N=76)=7.63, p=.006\right)$.

The 76 adolescents that had experience of both SASI and NSSI reported an average total of functions of $5.29(\mathrm{SD}=3.24)$ vs $3.68(\mathrm{SD}=3.30)$ for their NSSI and SASI, respectively $(\mathrm{t}=3.04, p=.003)$. The average number of reported automatic functions for the NSSI functions was $3.68(\mathrm{SD}=1.87)$ compared to $2.58(\mathrm{SD}=1.99)$ for the SASI functions $(\mathrm{t}$ $=3.51, p=.0006)$. The average reported NSSI functions in the social influence factor was $0.92(\mathrm{SD}=1.62)$ vs. $0.74(\mathrm{SD}=1.54)$ for the SASI functions, which was not significantly different $(\mathrm{t}=0.70, p=0.48)$.

Functions of NSSI among adolescents with NSSI only vs adolescents with both NSSI and SASI

Adolescents who reported experience of both NSSI and SASI had a pattern of more endorsed functions for their NSSI than did those who only reported NSSI. The automatic functions in particular were reported to a greater extent: "to relieve feeling numb or empty” $75.0 \%$ vs $46.9 \%\left(\chi^{2}(1, N=910 / 76)=22.13, p<.001\right)$, “to feel something even if it was pain” $53.9 \%$ vs $28.8 \%\left(\chi^{2}(1, N=910 / 76)=20.85, p<.001\right)$, "to get control of a situation" $53.9 \%$ vs $23.7 \%\left(\chi^{2}(1, N=910 / 76)=33.22, p<.001\right)$, “to punish yourself” $72.2 \%$ vs $36.4 \%$ $\left(\chi^{2}(1, N=910 / 76)=38.15, p<.001\right)$, "to stop bad feelings" 69.7 vs $38.1 \%\left(\chi^{2}(1, N=910 / 76)=\right.$ 29.06, $p<.001)$ and "to feel relaxed" $43.4 \%$ vs $18.6 \%\left(\chi^{2}(1, N=910 / 76)=26.59, p<.001\right)$. The social influence functions were also more commonly reported for NSSI among 
adolescents who had experience of both NSSI and SASI compared to those with only NSSI: “to try to get a reaction from someone, even if it's a negative reaction" 22.4 vs $10.4 \%\left(\chi^{2}\right.$ (1, $N=910 / 76)=9,91 p=.002$ ), "to get other people to act differently or change" $11.8 \%$ vs $4.1 \%$ $\left(\chi^{2}(1, N=910 / 76)=9.54, p=.006\right)$ and "to let others know how desperate you are" $14.5 \%$ vs $5.3 \%\left(\chi^{2}(1, N=910 / 76)=10.55, p<.004\right)$. More adolescents with both NSSI and SASI also endorsed the peer identification factor: "to give yourself something to do when with others" for their NSSI than those with only NSSI did, $5.3 \%$ vs $0.2 \%\left(\chi^{2}(1, N=910 / 76)=19.81, p\right.$ $<.001$ ). They also reported avoiding demands, such as "to avoid being with people" to a greater extent $10.5 \%$ vs $2.9 \%\left(\chi^{2}(1, N=910 / 76)=12.39, p=.003\right)$. Furthermore, significantly more adolescents with both NSSI and SASI endorsed the function "to give yourself something to do when alone” for their NSSI than those with only NSSI, $18.4 \%$ vs $5.4 \%\left(\chi^{2}\right.$ $(1, N=910 / 76)=29.50, p<.001)$.

Functions of SASI among adolescents with SASI only vs adolescents with SASI and NSSI

The adolescents with SASI only and those reporting both SASI and NSSI shared the same pattern of endorsed functions. However, one function relating to social influence: "to try to get a reaction from someone, even if it's a negative reaction" was more often reported among adolescents with only SASI, 34.1\% vs $13.2 \%\left(\chi^{2}(1, N=41 / 76)=7.20\right.$, $p=.007)$.

\section{DISCUSSION}

This study examined which functions adolescents endorsed for nonsuicidal selfinjury (NSSI) with behaviors such as cutting and burning skin, compared to which functions 
were reported by adolescents using sex as self-injury (SASI). Using sex as a deliberate means of injuring oneself is a largely unexplored area of research and many questions still remain as to how this behavior should be defined, conceptualized and delimited. Its relationship to other self-injurious behaviors, such as NSSI, also needs to be clarified. Examining whether adolescents endorse different or similar reasons for engaging in these different self-injurious behaviors is thus an important first step and a contribution to a field still lacking in empirical data. In the present study adolescents from a large community sample were classified in one of three groups based on their self-injury status: NSSI only $(n=910)$, SASI only $(n=41)$ and both NSSI and SASI $(n=76)$. The proportions of boys and girls were similar in the NSSI only and SASI groups, but among adolescents who reported both types of SIB (NSSI+SASI), there were fewer boys (22.8\%, 26.8 and $7.9 \%$ respectively). In the present study there was an overlap between the two forms of self-injury, with a majority of adolescents who reported using sex as a way of hurting themselves also endorsing NSSI $(65.0 \%, n=117)$. This is in line with earlier research which has also shown that there is an overlap of direct and indirect forms of self-injury, as well as different risky and maladaptive behaviors in adolescents (DiClemente et al., 1991; Duggan \& Heath, 2014; St. Germain \& Hooley, 2012). The findings can be summarized and discussed in six main points.

First, with regard to the functions endorsed for respective behaviors, automatic functions, i.e., to generate or regulate feelings or to punish oneself, were the most commonly reported functions in all three groups. Specifically, items "to relieve feeling numb or empty”, "to punish yourself" and "to stop bad feelings" were the three functions most frequently endorsed, irrespective of SIB category. This confirms well-established data, replicated in several studies (Klonsky, 2007; Lloyd-Richardson et al., 2007; Nock \& Prinstein, 2004; Wedig, 2014; Zetterqvist et al., 2013), which show that these functions are the main reason why adolescents engage in NSSI. There thus seems to be functional equifinality in these 
topographically different behaviors, in that they can be performed to achieve similar goals. This has previously been shown with regard to eating disorders and NSSI (Wedig, 2014; Wedig \& Nock, 2010), but has up to now been largely unexplored with regard to NSSI and using sex to self-injure.

Second, social functions (items "to try to get a reaction from someone, even if it’s a negative reaction”, “to get attention”, “to feel more a part of a group”) and, in addition, the item that refers to regulating loneliness and perhaps boredom: "to give yourself something to do when alone”, seems to be more closely related to using sex to injure oneself. Our interpretation of this functional item in the SASI context is that adolescents also seek the company of others and engage in sexual activity as a means of self-injuring to avoid being alone, and therefore associate it with a social function, although other interpretations of this item are plausible and need to be explored further. Significantly more adolescents in the group who only reported SASI endorsed these social functions compared to the NSSI only group. Specifically, "to try to get a reaction from someone, even if it's a negative reaction" was the fourth most commonly endorsed function (34.1\%) among those who used sex as a means of injuring themselves. Compared to the automatic functions, the social functions were less commonly endorsed in all three groups, and a similar result has previously been reported in connection with NSSI (Nock \& Prinstein, 2004; Zetterqvist et al., 2013). NSSI is typically a behavior performed in solitude and often kept secret from others, whereas the form of selfinjury where a sexual activity is deliberately engaged in to hurt oneself per definition involves other people, which could explain the relatively higher endorsement of social functional items in this group.

Third, significantly more NSSI social functions were endorsed by adolescents with both NSSI and SASI compared to those with only NSSI. Previous research has shown that social functions for NSSI are less commonly endorsed (Zetterqvist et al., 2013), and 
results from the present study preliminarily imply that certain social influence functions are reported by significantly more adolescents with experiences of only SASI compared to those with only NSSI, strengthening previous results on social functions. Interestingly, it would tentatively seem that adolescents with experience of both types of SIB (NSSI+SASI) have a greater need to regulate social experiences, for example to try to get help, to get others to understand how desperate they are and act differently toward them, to get a reaction from someone or by decreasing social demands, and that NSSI also meets social functions in this group.

Fourth, among individuals with both forms of SIB, significantly more adolescents endorsed automatic functions for their NSSI compared to adolescents with only NSSI. This perhaps indicates a need to escalate the self-injurious behavior in order to find relief from an unbearable state of mind. This combined SIB group could potentially be more burdened with unmanageable negative emotions and therefore NSSI on its own is no longer sufficient to regulate emotions.

Fifth, adolescents who only reported engaging in sex as a means of deliberately injuring themselves reported a significantly higher total number of functions, as well as a higher number of automatic functions for this behavior compared to the NSSI functions for adolescents with only NSSI. The feeling generation/anti-dissociation functions in the automatic factor of NSSI have previously been associated with posttraumatic stress in adolescents (Nock \& Prinstein, 2005), indicating that experience of trauma, posttraumatic stress and dissociation in adolescents with SASI could be an area for further studies.

Sixth, significantly more adolescents who reported both forms of self-injury endorsed several of the automatic functions for their NSSI, more than for their SASI. This group reported more severe NSSI, more cutting and several different NSSI methods 
compared to those with only NSSI, indicating a more burdened and distressed group, compelled to engage in several different forms of self-injury. For adolescents with both selfinjurious behaviors, NSSI seems to be more clearly associated with automatic functions than is SASI. Methodologically, the functional items for NSSI came before the functional assessment of SASI in the questionnaire. A clear majority of adolescents with both forms of behavior thus first endorsed automatic functions for their NSSI, which is possibly why fewer adolescents endorsed automatic functions for SASI later on in the questionnaire, Those with NSSI+SASI reported the highest number of total functions. In addition these adolescents reported the highest percentage for automatic functions, indicating a high need for affect regulation. Specifically, the high endorsement of all NSSI automatic functions in combination with the highest number for most of the NSSI functions is in all likelihood associated with the fact that they were the group with the most severe NSSI. Previous studies have shown that more frequent, severe and diverse NSSI increases the number of functions (Lloyd-Richardson et al., 2007).

Taken as a whole, the higher number of functions endorsed and the higher endorsement of automatic functions for NSSI as well as the fact that the adolescents had resorted to sex as self-injury leads to speculation about the etiology and nature of earlier life experience in this group. Perhaps this is a more traumatized population, specifically with regard to sexual abuse. The behavior also needs to be seen in the context of re-traumatization and reenactment seen in trauma populations with possible symptoms of PTSD and dissociation, which would account for the high endorsement of automatic functions. This is the focus of a forthcoming study, which will contribute further to this research area, currently in paucity of empirical data.

Finally, we have avoided categorizing SASI as a direct or indirect form of selfinjury. One argument for the direct form of self-injury is the immediate relationship in time 
between action (having sex) and function, especially the automatic functions, and also the fact that in another study from the same sample (Svedin, Priebe, Wadsby, Jonsson \& Fredlund, 2015), the majority (68\%) of those who used sex as self-injury reported pain associated with the activity. Sex as self-injury could also be considered a "direct" form since actual physical harm occurs without any intervening steps (Nock, Cha \& Dour, 2010) even though, apart from pain, it is difficult to establish alteration of body tissue. The direct and deliberate destruction of body tissue is central to direct self-injurious behavior according to the definition of NSSI, and this highlights the fact that we do not have detailed knowledge or understanding of the actions and the consequences to body tissue that result from SASI. This means that there is perhaps more support for the supposition that SASI should belong to the group of behaviors labelled as indirect self-injury behavior, in accordance with the suggested definition of St. Germain \& Hooley (2012). On the other hand, the behavior might include both cases: with and without tissue damages, indicating that SASI can best be seen as a continuum of behavior ranging from indirect to direct self-injurious behavior. Further studies are needed.

This study taps into the work of Hooley and St. Germain (2014), who discuss the relationship between direct and indirect self-injury and present three models for how the behaviors might be related: they can be seen either as alternative forms of self-destructive behaviors, as differing in severity or as distinct conditions. The present data show support for functional equivalence, where automatic functions were most commonly endorsed by all three groups of adolescents. Data thus support the idea that it can be fertile to use a functional approach in the examination of self-injurious behaviors (Wedig, 2014), and also that individuals can alternate between a variety of SIB methods to achieve the goal of emotion regulation. Interestingly, data also lend support to certain distinct psychological characteristics, in that some specific social functions (mainly directed toward getting other 
people to react to one's situation, to get attention, to feel part of a group, to have something to do when alone and to potentially reduce boredom or loneliness) were more common among adolescents with only SASI, compared to those who only engaged in NSSI. More studies are needed that can add further information to these preliminary data.

\section{Conclusion}

Despite being topographically different and, as such, distinct behaviors, NSSI and SASI share many functions. Automatic functions referring to behaviors such as to relieve feeling empty and numb, to stop bad feelings and to punish oneself were the three functions most frequently reported, irrespective of type of self-injurious behavior endorsed. There thus seems to be functional equivalence between these behaviors. There were, however, also differences between groups. Significantly more adolescents who reported sex as a way of hurting themselves endorsed social influence functions than did adolescents with NSSI only. This social aspect has to do with the nature of the self-injurious behavior chosen; abusive sex is per definition more social than NSSI, which is usually performed in solitude. This is supported by the fact that more adolescents endorsed the functions "to try to get a reaction from someone even if it's a negative reaction", "to get attention", "to feel more a part of a group” and "to give yourself something to do when alone”.

\section{Limitations}

The data has been collected through self-report which has a well-known bias with regard to recall, and thus potentially influences validity. The FASM was originally developed to measure the functions of NSSI but is also used in this study to measure the functions of sex as self-injury, which has not previously been done. The internal consistency 
for the factors avoiding demands $(\alpha=.60)$ and peer identification $(\alpha=.53)$ of the FASM when assessing SASI functions was relatively low. These factors only contain a few items, which could explain the lower alpha value, in combination with the fact that the FASM was not originally developed for SASI functions. The similarities in functions between groups could be explained by the fact that the same instrument was used. If different functions had been included it might have resulted in more differences between groups. It does, however, seem to have been a useful method to assess functions of both behaviors in this first explorative investigation.

The use of an instrument originally developed for NSSI with a set list of functions can be problematical and affect the results by limiting choices for the SASI group. It is possible that there are some functions that adolescents with SASI would endorse that individuals with NSSI might not even consider, and which have thus been overlooked due to the design of the present study. To our knowledge no previous studies have been published on the functions of SASI, and the preliminary results from our study need to be confirmed by additional qualitative studies. The FASM has, however, previously been used successfully in a sample of individuals with eating disorders (Wedig \& Nock, 2010).

Another limitation is that we do not know which behavior came first, i.e., if adolescents started with NSSI and then progressed to SASI or the other way around. Clinical interviews with adolescents who have experience of both behaviors have reported similar functions and that their SASI had a later debut than NSSI (Jonsson et al., 2015). Other forms of destructive, maladaptive risky behaviors were not assessed, which would have been an interesting step in the process toward a conceptualization of SASI. Statistically there were multiple comparisons, which increases the risk for type I errors, especially with an explorative approach, which is why significances at the 0.05 level were not highlighted in the text. Furthermore, cell sizes for some of the less common functions were very small and 
Fisher's exact test was used. In these cases the tests of significances have to be interpreted with caution, due to questionable validity. Finally, the assessment of SASI has some limitations since only one item was used without providing further explanation of the behavior.

\section{Clinical Implications}

Since there is support for a co-occurrence of different self- injurious behaviors, it is advisable in clinical practice to assess several different forms when one or more have been reported by adolescents. There is generally some reluctance to reveal socially unacceptable behaviors, and without active questioning there might be a risk of underidentification.

It is thus important to assess both indirect and direct types of SIB. Individuals with several self-destructive behaviors are usually a particularly distressed group, with a need to regulate emotional difficulties. A functional approach can be useful when designing clinical interventions. Emotion regulation deficits are an underlying cause of many SIB, and attention should therefore be paid to increasing such skills in the context of both direct and indirect self-injury. Increasing social skills for receiving human attention, help, achieving a sense of togetherness with others and strengthening relationships also seem to be important, together with directing interventions to the social context to prevent the need for self-abusive destructive behaviors. 


\section{REFERENCES}

AMERICAN PSYCHIATRIC ASSOCIATION (2013). Diagnostic and Statistical Manual of Mental Disorders (5th ed.). Washington DC: Author.

BRAUSCH, A. M., \& MUEHLENKAMP, J. J. (2014). Experience of the body, pp 237253. In: Non-suicidal self-injury in eating disorders. Advances in etiology and treatment. L. Claes \& J.J. Muehlenkamp (Eds.). Springer-Verlag Berlin Heidelberg.

BROWN, M. Z., COMTOIS, K.A., \& LINEHAN, M. M. (2002). Reason for suicide attempts and nonsuicidal self-injury in women with borderline personality disorder. Journal of Abnormal Psychology, 111, 198-202.

CHAPMAN, A. L., \& DIXON-GORDON, K. L. (2007). Emotional antecedents and consequences of deliberate self-harm and suicide attempts. Suicide and Life-Threatening Behavior, 37, 543-552.

CLAES, L., \& MUEHLENKAMP, J. J. (2014). Non- suicidal self-injury and eating disorder: Dimensions of self-harm. In: Non-suicidal self-injury in eating disorders. Advances in etiology and treatment. L. Claes \& J. J. Muehlenkamp (Eds.). Springer- Verlag: Berlin Heidelberg.

CLAES, L., \& VANDEREYCKEN, W. (2007). Self-injurious behavior: differential diagnosis and functional differentiation. Comprehensive Psychiatry, 48, 137-44. Review. Erratum in: Comprehensive Psychiatry, 48, 394.

COOPER, M. L., SHAPIRO, C. M., \& POWERS, A. M. (1998). Motivations for sex and risky sexual behavior among adolescents and young adults: A functional perspective. Journal of Personality and Social Psychology, 75, 1528-1558.

DAHLSTRÖM, Ö., ZETTERQVIST, M., LUNDH, L. G., \& SVEDIN, C. G. (2015). Functions of nonsuicidal self-injury: exploratory and confirmatory factor analyses in a large community sample of adolescents. Psychological Assessment, 27, 302-13.

DICLEMENTE, R. J., PONTON, L. E., \& HARTLEY, D. (1991). Prevalence and correlates of cutting behavior: risk for HIV transmission. Journal of the American Academy of Child and Adolescent Psychiatry, 30, 735-739. 
DUGGAN, J. M., \& HEATH, N. L. (2014). Co-occurring health-risk behaviors of nonsuicidal self-injury in eating disorder. In Advances in etiology and treatment. L. Claes \& J. J. Muehlenkamp (Eds.). Springer- Verlag Berlin Heidelberg.

ESPOSITO, C., SPIRITO, A., BOERGERS, J., \& DONALDSON, D. (2003). Affective, behavioral, and cognitive functioning in adolescents with multiple suicide attempts. Suicide and Life- Threatening Behavior, 33, 389-399.

FAVARO, A., FERRARA, S., \& SANTONASTASO, P. (2007). Self-injurious behavior in a community sample of young women: relationship with childhood abuse and other types of self-damaging behaviors. Journal of Clinical Psychiatry, 68, 122-31.

GUERTIN, T., LLOYD-RICHARDSON, E., SPIRITO, A., DONALDSON, D., \& BOERGERS, J. (2001). Self- mutilative behavior in adolescents who attempt suicide by overdose. Journal of the American Academy of Child and Adolescent Psychiatry, 40, 10621069.

HOOLEY, J. M. \& ST. GERMAIN, S.A. (2014). Should we expand the conceptualization of self-injurious behavior? Rationale, review, and recommendations. p. 4758. In The Oxford Handbook of suicide and self-injury. Editor M. K. Nock. Oxford University Press.

INTERNATIONAL SOCIETY FOR THE STUDY OF SELF-INJURY. (2007). Definition of non-suicidal self-injury. http://www.itriples.org/isss-aboutself-i.html

JENSTAV, M., \& MEISSNER, M. (2016). “Jag önskar att jag vågat prata med någon" - Om att få stöd och hjälp ur ett sexuellt självksadebeteende ["I wish I dare to talk to someone"- About receiving support and help out of a sexual self-injury behavior]. Stockholm: Stockholms Tjejjour.

JONSSON, L., \& LUNDSTRÖM MATTSSON, Å. (2012). Unga som skadar sig genom sex.[Youth who self-harm by sex.] Stockholm: Stiftelsen Allmänna Barnhuset.

JONSSON, L. S., SVEDIN, C. G., \& HYDÉN, M. (2015). Young women selling sex online - narratives on regulating feelings. Adolescent Health Medicine and Therapeutics, 6, 17-27. 
KLONSKY, E. D. (2007). The functions of deliberate self-injury: a review of the evidence. Clinical Psychology Review, 27, 226-239.

LLOYD, E. E., KELLEY, M. L., \& HOPE, T. (1997). Self-mutilation in a community sample of adolescents: Descriptive characteristics and provisional prevalence rates. Poster session presented at the annual meeting of the Society for Behavioral Medicine, New Orleans, LA.

LLOYD-RICHARDSON, E. E., PERRINE, N., DIERKER, L., \& KELLEY, M. L. (2007). Characteristics and functions of non-suicidal self-injury in a community sample of adolescents. Psychological Medicine, 37, 1183-1192.

MØHL, B., LA COUR, P., \& SKANDSEN, A. (2014). Non- suicidal self-injury and indirect self-harm among Danish high school students. Scandinavian journal of child and adolescent psychiatry and psychology 2(1), 11-18.

MUEHLENKAMP, J.J., CLAES, L., HAVERTAPE, L., \& PLENER P.L. (2012). International prevalence of adolescent non-suicidal self-injury and deliberate self-harm. Child and adolescent psychiatry and mental health 30, 6-10.

NOCK, M. K., CHA, C. B., \& Dour, H. J. (2010). Disorders of impulse- control and self- harm. In D. H. Barlow (Ed.), Oxford handbook of clinical psychology (p.p. 504-529). New York: Oxford University press.

NOCK, M. K. (2010). Self-injury. Annual Review of Clinical Psychology, 6, 339-363.

NOCK, M. K., \& PRINSTEIN, M. J. (2004). A functional approach to the assessment of self- mutilative behavior. Journal of Consulting and Clinical Psychology, 72, 885-890.

NOCK, M.K., \& PRINSTEIN, M. J. (2005). Contextual features and behavioral functions of self-mutilation among adolescents. Journal of Abnormal Psychology, 114, 140-146.

NOCK, M. K., HOLMBERG, E. B., PHOTOS, V. I., \& MICHEL, B. D. (2007). SelfInjurious Thoughts and Behaviors Interview: Development, reliability, and validity in an adolescent sample. Psychological Assessment, 19, 309-317. 
PENN, J. V., ESPOSITO, C. L., SCHAEFFER, L. E., FRITZ, G. K., \& SPIRITO, A. (2003). Suicide attempts and self-mutilative behavior in a juvenile correctional facility. Journal of the American Academy of Child and Adolescent Psychiatry, 42, 762-769.

ST GERMAIN, S. A., \& HOOLEY, J. M. (2012). Direct and indirect forms of nonsuicidal self-injury: Evidence for a distinction. Psychiatry Research, 197, 78-84.

STATISTICS SWEDEN. (2014). http://www.statistikdatabasen.scb.se. Accessed 10 May 2015.

SVEDIN, C. G., \& PRIEBE, G. (2004). Ungdomars sexualitet-attityder och erfarenheter. Avsnitt: Sexuell exploatering. Att sälja sex mot ersättning/pengar. [Young persons sexuality, attitudes and experiences. Section: Sexual exploitation. Selling sex for money] In Statens offentliga utredningar, sexuell exploatering av barn i Sverige [Sexual exploitation of children in Sweden]. SOU 2004_71. Stockholm: Regeringskansliet.

SVEDIN, C. G., \& PRIEBE, G. (2009). Unga, sex och Internet i Ungdomsstyrelsen 2009:9 (Ed). Se mig. Unga, sex och Internet [Young persons, sex and the Internet. In the Swedish National Board for youth affairs 2009:9 (Ed.), See Mee. Young people on sex and the Internet]. p.p 32-143. Stockholm: Ungdomsstyrelsen.

SVEDIN, C. G., PRIEBE, G., WADSBY, M., JONSSON, L., \& FREDLUND, C. (2015). Unga, sex och Internet- i en föränderlig värld. [Young persons, sex and the Internetin a changing world]. Linköping: Linköping University.

SVENSSON, F., FREDLUND, C., SVEDIN, C. G., PRIEBE, G., WADSBY, M. (2013). Adolescents selling sex: exposure to abuse, mental health, self-harm behaviour and the need for help and support--a study of a Swedish national sample. Nordic Journal of Psychiatry, 67, 81-88.

TULL, M. T., WEISS, N. H., ADAMS, C. E., GRATZ, K. L. (2012). The contribution of emotion regulation difficulties to risky sexual behavior within a sample of patients in residential substance abuse treatment. Addictive Behaviors, 37, 1084-1092.

ZETTERQVIST, M., LUNDH, L.G., DAHLSTRÖM, Ö., \& SVEDIN, C. G. (2013). Prevalence and function of non-suicidal self-injury (NSSI) in a community sample of adolescents: using suggested DSM-5 criteria for a potential NSSI disorder. Journal of Abnormal Child Psychology 41(5), 759-73. 
WEDIG, M. M. (2014). Psychological meanings and functions of non-suicidal selfinjury and eating disorders. pp 73-84. In Non-suicidal self-injury in eating disorders.

Advances in etiology and treatment. L. Claes \& J.J. Muehlenkamp (Eds.). Springer-Verlag Berlin Heidelberg.

WEDIG, M. M, \& NOCK, M. K. (2010). The functional assessment of maladaptive behaviors: a preliminary evaluation of binge eating and purging among women. Psychiatry Research, 178, 518-24. 


\section{Figure 1}

\section{Flowchart of participants}

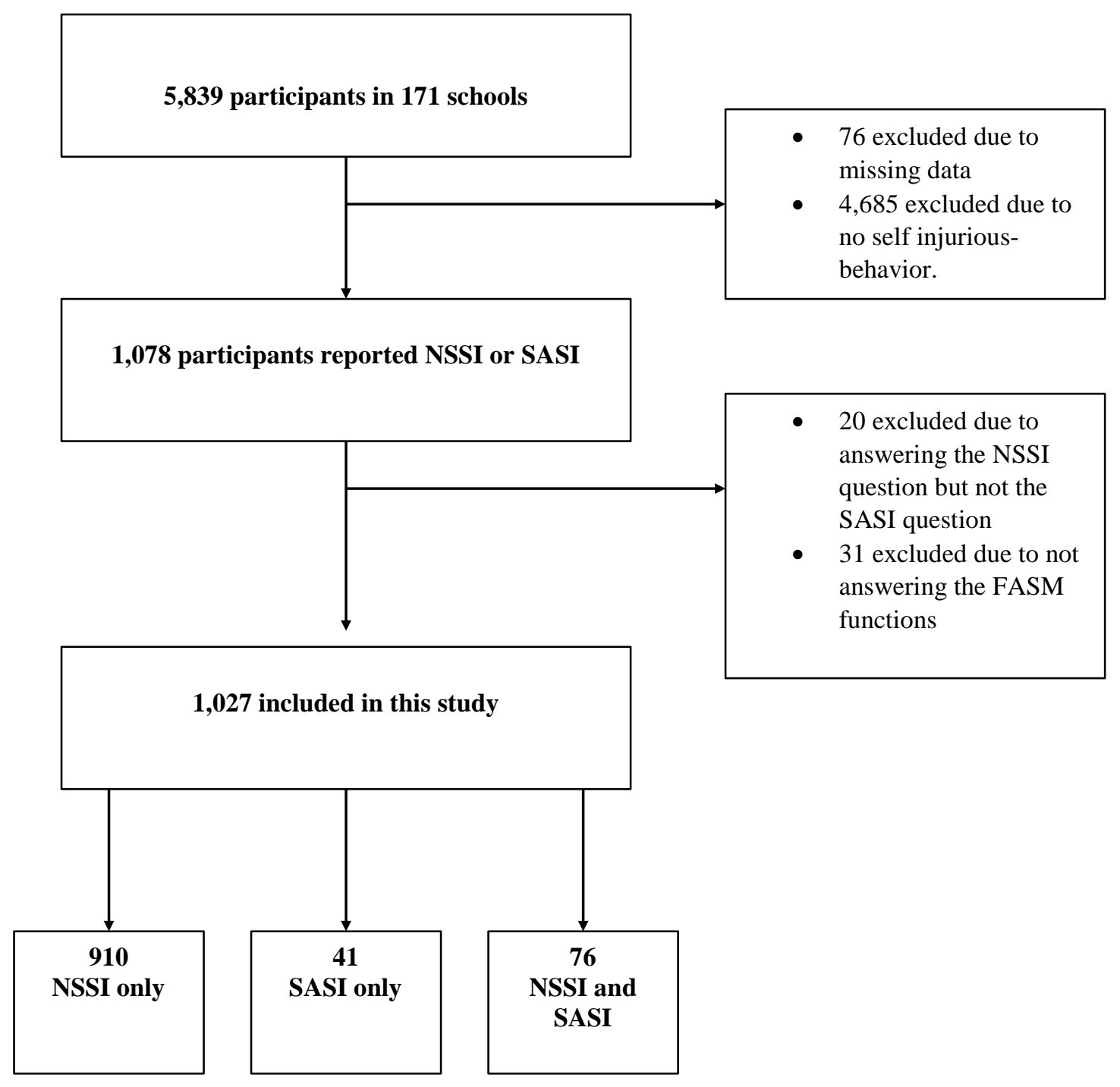

Note: NSSI = nonsuicidal self-injury, SASI = sex as self-injury 
Table 1.

Background data and socio-demographic variables for adolescents with nonsuicidal selfinjury (NSSI) and/or sex as self-injury (SASI) and adolescents with neither NSSI nor SASI.

\begin{tabular}{|c|c|c|c|c|c|c|c|}
\hline & \multicolumn{2}{|c|}{$\begin{array}{l}\text { With NSSI and/or } \\
\text { SASI }\end{array}$} & \multicolumn{2}{|c|}{$\begin{array}{l}\text { With neither NSSI } \\
\text { nor SASI }\end{array}$} & \multirow[t]{2}{*}{$\chi^{2}$} & \multirow[t]{2}{*}{$d f$} & \multirow[t]{2}{*}{$p$-value } \\
\hline & $n$ & $\%$ & $n$ & $\%$ & & & \\
\hline Total number of participants & 1027 & 18.0 & 4685 & 82.0 & & & \\
\hline \multicolumn{8}{|l|}{ Gender } \\
\hline Boy & 224 & 21.8 & 2301 & 49.1 & 255.7 & 2 & $<.001$ \\
\hline Girl & 787 & 76.6 & 2346 & 50.1 & & & \\
\hline This division doesn't fit me & 16 & 1.6 & 37 & 0.8 & & & \\
\hline Study program & & & & & & & ns \\
\hline Theoretical & 731 & 71.2 & 3333 & 71.1 & & & \\
\hline Practical & 296 & 28.8 & 1352 & 28.9 & & & \\
\hline Fathers working & 860 & 84.4 & 4144 & 88.6 & 14.2 & 1 & $<.001$ \\
\hline Mothers working & 885 & 87.1 & 4080 & 87.3 & & & ns \\
\hline $\begin{array}{l}\text { Fathers with university } \\
\text { education }\end{array}$ & 372 & 36.4 & 1918 & 41.1 & 7.8 & 1 & .005 \\
\hline $\begin{array}{l}\text { Mothers with university } \\
\text { education }\end{array}$ & 534 & 52.1 & 2443 & 52.3 & & & ns \\
\hline Financial situation in the family & & & & & 20.3 & 2 & $<.001$ \\
\hline Good & 954 & 93.0 & 4421 & 94.4 & & & \\
\hline Poor & 45 & 4.4 & 97 & 2.1 & & & \\
\hline Do not know & 27 & 3.6 & 165 & 3.5 & & & \\
\hline $\begin{array}{l}\text { Adolescents with immigrant } \\
\text { background }\end{array}$ & 82 & 8.0 & 414 & 8.8 & & & ns \\
\hline $\begin{array}{l}\text { Fathers with immigrant } \\
\text { background }\end{array}$ & 209 & 20.4 & 1237 & 21.7 & & & ns \\
\hline $\begin{array}{l}\text { Mothers with immigrant } \\
\text { background }\end{array}$ & 208 & 20.3 & 1023 & 21.8 & & & ns \\
\hline Living situation & & & & & 46.1 & 3 & $<.001$ \\
\hline With both parents or alternating & 650 & 63.5 & 3425 & 73.1 & & & \\
\hline $\begin{array}{l}\text { With one parent with or without } \\
\text { new partner (step-parent) }\end{array}$ & 265 & 25.9 & 955 & 20.4 & & & \\
\hline Alone or with siblings or partner & 96 & 9.4 & 281 & 6.0 & & & \\
\hline In foster care or institution & 13 & 1.3 & 22 & 0.5 & & & \\
\hline
\end{tabular}


Table 2. Functions of nonsuicidal self-injury (NSSI) and sex as self-injury (SASI).

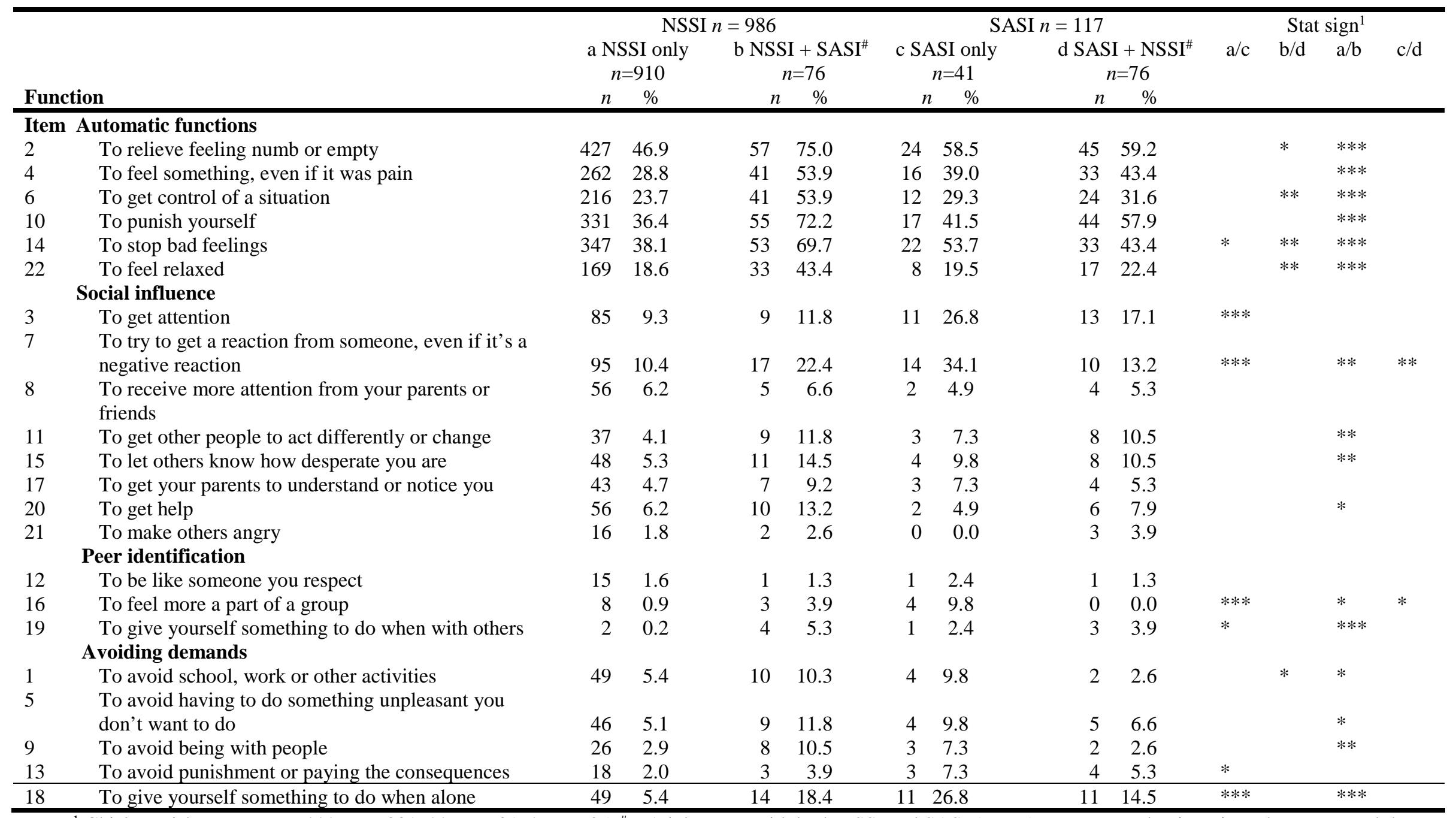

Notes: ${ }^{1}$ Chi-2 or Fisher exact test, ${ }^{* * *}=\mathrm{p}<.001,{ }^{* *}=\mathrm{p}<.01, *=\mathrm{p}<.05 .{ }^{*}=$ Adolescents with both NSSI and SASI $(n=76)$ are presented twice, since they answered the questions concerning the functions of NSSI and the functions of SASI separately. 